\title{
Healthcare Organizational Silence: Who is Accountable?
}

\section{Adnan Yaqoob* and Seren Amin Muhammad}

School of Nursing and Midwifery, Aga Khan University, Karachi, Pakistan

*Corresponding author: Adnan Yaqoob, School of Nursing and Midwifery, Aga Khan University, Karachi, Pakistan, Tel: 00923135522694; E-mail: adnan.yaqoob.mn17@student.aku.edu

Received date: January 17, 2018; Accepted date: February 02, 2018; Published date: February 05, 2018

Copyright: $@ 2018$ Yaqoob A, et al. This is an open-access article distributed under the terms of the Creative Commons Attribution License, which permits unrestricted use, distribution, and reproduction in any medium, provided the original author and source are credited.

\begin{abstract}
Policies and protocols are set to be the benchmark of every organization which brings it towards the mission to meet its vision. Organization without policies or its implementation seems blind in terms of its operation and administration. However, lack of implementation of policies can endorse unethical decisions which mislead the entire organization's mission and can develop mistrust among the employees that may ultimately breach the principle of ethics.
\end{abstract}

Keywords: Organizational silence; Health care provider; Nonmaleficence; Organizational ethics; Policies; Unethical decisions; Negligence; Nonfeasance

\section{Scenario}

This paper is based on a 45 years old female patient who landed up in Emergency department. Her heart rate and blood pressures were undetectable. Cardiopulmonary Resuscitation (CPR) was initiated and rush call was generated. Being a member of resuscitation team, I observed that all team members were reached on time, except one. We all were waiting for the member who was responsible to place endotracheal tube. But he/she did not arrive, even after making several calls on his/her personal number. During 35 min of CPR, patient revived twice. Urgent chest X-ray was obtained which showed huge aspiration and pulmonary edema. Her oxygen saturation was $40-45 \%$. Patient was put on bag mask ventilation which appeared to be ineffective. So, we all reached to this consensus that the patient needs advance airway but due to the confines on our other resuscitation team members by the consultant we could not intubate the patient and ultimately patient expired.

This occurrence of unavailability of concern Health Care Provider (HCP) and restriction on other resuscitation team members to place endotracheal tube is seen very frequently. It was reported many a times but no action is been taken by the authorities and still this practice moves on for which no one is held accountable.

\section{Introduction}

Organizational domination ascends through effective ethical decision making, integration of process and support systems which enable organizational culture and environment. The relationship of these ethical components within an organization is very complex and variable.

The role of ethics in health care organization begins with health care beliefs, expectations, ethical reflections and decision making. Besides this, the ethics is deep-rooted with organizational culture and environment which makes stronger base and then grows simultaneously to build up with processes and systems with supporting structure such as policies and procedures which allow the actions to do with ease [1].

\section{$1^{\text {st }}$ Position (From the lens of organization)}

In reputable organizations, health care providers (HCPs) follow the organizational ethics; respect the patients' values and moral beliefs. They perform actions with sincerity based on the standards of practice by keeping all the principles of ethics in mind [2].

Likewise, Organizational policies have a great effect on practices or we can say that practices can be corrected if organizations have transparent policies [3]. If organizations rely on one's personal decision, other than policies, then it shows that organization is not able to make and implement policies which may lead to malpractices and causes harm to the patients.

Moreover, when procedures are not handy to the entire organization, redundancy quickly becomes an issue. When work is done inaccurately or its evaluation is not done then actions require correction. When organization does not reflect upon its actions, it becomes the culture of that organization. This can lead to loss of trust and development of misperceptions about the organization.

To maintain these standards of practice, all policies should exist within organization system which every HCP can have access on [4] In our scenario, there was no written policy of endotracheal intubation that who should place it, and if healthcare provider cannot reach due to any reason, then who will take this role. Patient was died who required endotracheal intubation due to huge pulmonary edema. But, instead of making the policy, organization relied on someone's verbal order which violated the principles of ethics and harmed the patient. It shows organizational failure and incompetency of authorities.

After internalizing the scenario, it came out of my mind that this incident was just because of that decision by consultant which puts many patients in danger. If any experienced HCP other than designated one has tried to place the endotracheal tube and tube was confirmed to be placed correctly then still that HCP was threatened to be terminated just because he did not wait for that team member.

In a research conducted by Vodera, reasons of organizational silence were reported that inhibit internal reporting. Those reasons are: 
unavailability of resource system, hostile or unethical organizational culture, toxic leadership and lack of organizational justice. For creating the ethical organizational culture, three most essential steps are required. First is to implement policies that apparently defend internal reporting. Second step is to include ethics under the umbrella of core organizational values. And last but not the least; leaders must be active listeners and role models of integrity.

\section{$2^{\text {nd }}$ Position (From the lens of healthcare provider)}

Ethics has a logical and factorial assessment of standards, values and beliefs which find outs the way to determine correct application of decisions and actions. Ethics is not based on someone's wishes or gut reactions, but it reasonably weighs up the risks and benefits to deal with problem. Moreover, values and ethics are central to positive organizational performance [5].

In addition, violation of principles of ethics and providing harm to patient by HCP is the evidence of going against Hippocratic Oath which says:

"I will remember that I do not treat a fever chart, a cancerous growth, but a sick human being, whose illness may affect the person's family and economic stability. My responsibility includes these related problems, if I am to care adequately for the sick. I will prevent disease whenever I can, for prevention is preferable to cure".

On the other hand, HCPs like nurses have their pledge as well which says:

"I will do all in my power to elevate the standards of my profession and I will hold in confidence all personal matters that are committed to my keeping. I will work to prevent disease and to promote wellness in individuals, families, and communities".

However, due the restriction on other HCPs including nurses in emergency department were also forced to go against their pledge which is the result of some one's negative power in an organization hence proved failure of organizational ethics.

In other words, this restriction on health care providers who stand for the benefit for their patients is becoming crime now. Because they were forced to go against the principle of beneficence, if we take this practice under the guidelines recommended by AHA [6], which says "advance airway devices are frequently placed by experienced providers during CPR if bag-mask ventilation is inadequate or as a stepwise approach to airway management".

If we analyze, AHA does not recommend that only one discipline in hospital is eligible to place endotracheal intubation but the person who is confident enough to place it with minimal interruptions in chest compressions. The health care provider who was supposed to take this role is also accountable for not performing the expected task. Even though he/she knew that other members of resuscitation team are not allowed to place endotracheal tube. So HCP's presence was mandatory or he/she could have delegated this task to any other HCP whom he/she considered as expert in his/her absence.

In a review conducted by Trevino [7] some reasons of employee silence were reported that inhibit employees to speak up when any issue arises. One of those reasons is the concern that in spite of reporting the issue nothing will be done against it. This leads to lack of self-efficacy (the idea that one has confidence and ability to speak up) and employee lack of interest in organizational issues because they face non serious attitude from authorities.
On contrary, the decision of consultant may also be correct in terms of the injury to the patient (non maleficence). As endotracheal intubation have many risks and complications, such as, disruption of the laryngotracheal junction, tear of the trachea, laryngeal injury and esophageal intubation. So it must be place by experienced person to reduce injury and decrease hand off time. Moreover, the HCP might be engaged with other patients and it may be the reason of his/her non availability at the time of resuscitation.

\section{Justification of My Positions}

My viewpoint is strongly in the favor of allowing all the members of resuscitation team to place endotracheal tube so that patient can be managed without waiting for someone. HCP's should be trained by the same disciplines who consider themselves as having expertise in placing the endotracheal tubes.

If we analyze the decision which was taken by the consultant, then it goes against the principal of ethics. Because, it causes delay for those patients who required urgent intubation. According to medial law and ethics "A patient shows symptoms of some illness or disorder, but the doctor decides, for whatever reason, to delay treatment then this is considered as negligence". This decision may not be intended to do harm to the patient but in reality, the patients are getting harm in terms of delayed intervention (Nonfeasance). Therefore, presence of other resuscitation team members have no worth in this regards. This causes guilt in them that they could have saved the patient if the airway was managed early.

\section{Possible Consequences}

Practices without written policies and protocols are just actions that can victimize the HCPs that whether they should go ahead for the intervention or not. This dilemma occurred between two principles of ethics. One is from the side of consultant in terms of prevention to injury (non maleficence) and the other is from the side of HCP in terms of saving the patient's life (beneficence). These immoral actions can be harmful for the organization's reputation. Committing medical negligence and breaching the principle of non-maleficence can lead to bear penalties and medical lawsuits. While actions are taken based on standards of practices, then it takes this dilemma away and eventually makes organizations more ethically justifiable.

\section{Recommendations}

\section{Whistle blowing}

HCP who witnesses such incidents should take the role of whistle blower. Every organization demands honesty from and among its employees. By creating a whistle blowing culture, employees feel comfortable in speaking up, when necessary. To create and promote a whistle blowing culture, following actions should be implemented: Organizations should make and implement a policy for whistle blowing. Top management must ensure the practice of whistle blowing in the culture. A complete inquiry should be done once a whistle blowing event is reported and authorities should discuss personal thoughts of employees with them to make a similar mindset throughout.

However there are some other recommendations which can smoothen the system's procedure. Firstly, all HCPs should follow the code of ethics and no decision should go against the organizational 
Citation: Yaqoob A, Muhammad SA (2018) Healthcare Organizational Silence: Who is Accountable?. J Clin Res Bioeth 9: 321. doi:

Page 3 of 3

mission, vision, and culture. Moreover, policies should be developed to guide the practices in correct direction and standards of practice should be clear to all HCPs. The authorities should stay autonomous to take action if such incidents occur frequently rather favoring someone's feelings and reactions. In addition, Clinical Ethics Committee should involve in such decisions to take neutral part that will decrease the occurrence of incident. Code analysis should be done by unit management team to find out the gaps for further improvement and training sessions must be conducted for everyone in the resuscitation team. Likewise, monitoring system should be developed in hospitals to measure the performance and practice of HCPs in order to avoid these types of incidents in future. For instance, when the crash calls are generated, one call should be given to the person in quality department so that being a neutral person, he/she can come at the location and evaluate the process.

\section{Conclusion}

Organizational silence leads to endorsement of unethical decision. As a result, variation in practices at several places of a single organization is seen. However, Public and philanthropic organizations have less implementation of policies and protocols, as compare to private sectors. It does not mean that only profit or private organizations should implement the policies just because people who are paying the cost do demand quality health care services. But, the public and philanthropic organizations should also take it into account. Because, organizational ethics should be synchronized with health care services, so that everyone can avail rather for sale. Whether, they are at private, public or philanthropic organization.

\section{References}

1. Frolic FA (2010) Ethics Framework. Hamilton Heath Sciences.

2. Veatch RM (2006) How philosophy of medicine has changed medical ethics. J Med Philos 31: 585-600.

3. Irving AV (2014) Policies and Procedures for Healthcare Organizations: A Risk Management Perspective. Patient Safety and Quality Health Care.

4. Cinar F, Eren E (2013) Innovative approach to the ethics in health care organizations. Social Behav Sci 99: 719-725.

5. Grosenick LE (1994) Governmental ethics and organizational culture. In: Cooper TL (ed) Handbook of administrative ethics. New York: Marcel Dekker, pp. 183-197.

6. American Heart Association (2015) Guidelines update for Cardiopulmonary Resuscitation and Emergency Cardiovascular Care.

7. Trevino LK, Weaver GR, Gibson DG, Toffler BL (1999) Managing Ethics and Legal Compliance. Calif Manage Rev 41: 131-151. 